\title{
RISK DRIVERS OF FALSIFIED AND SUB-STANDARD MEDICINES IN EAST AFRICA: PERCEPTIONS AND PRACTICES OF PHARMACEUTICAL DRUG FACILITY OWNERS/EMPLOYEES
}

\author{
Available online at www.ijdra.com \\ REVIEW ARTICLE \\ ${ }^{1}$ Fomundam Henry* ${ }^{1}$ Tesfay A, ${ }^{2}$ Maranga A, ${ }^{2}$ Oyaro F, ${ }^{3}$ Kambafwile H. \\ ${ }^{1}$ Howard University, Regional Office, Pretoria, South Africa. \\ ${ }^{2}$ Howard University ,Office, Nairobi, Kenya \\ ${ }^{3}$ Independent Consultant \\ *Corresponding Author's E-mail: Hfomundam@aol.com
}

\begin{abstract}
An interview survey was conducted among drug shop owners to investigate the access to and perception of counterfeit medication along transport corridors of East Africa spanning Kenya, Tanzania, Uganda and Democratic Republic of Congo. Owners of 171 retail drug outlets of modern medicines were interviewed on their knowledge, perception, and practices related to counterfeit medicines. Forty-four (44) encounters with counterfeit medicines were reported. Twenty-two (22) of the 171 interviewed drug store owners said that quality was the least important aspect they considered when procuring drugs. Generally, $65.9 \%$ of the drugs were sourced from registered wholesalers and distributors while the remaining $34.1 \%$ were supplied by unregistered in-country or cross-border sales representatives. In all the four countries, the 10 fastest moving drugs were reported to originate from 27 different countries with most (39\%) from India. From 171 interviewees, 135 acknowledged that they were aware of the existence of counterfeit drugs, 106 of whom attributed their level of awareness to mass media. Only 32 of the interviewees reported having received any formal training on counterfeit medicines at seminars or workshops. 160 of the interviewees acknowledged that counterfeit drugs pose a major threat to the patient and pharmaceutical market. The region has a plethora of drug outlets run by attendants with varying backgrounds, diverse knowledge on medicines and practice patterns. There is an urgent need for medicine regulators and other stakeholders in Africa involved in medicine safety, to focus on properly regulating these outlets and also standardizing and training the drug outlet personnel.
\end{abstract}

Keywords: Counterfeit, Falsified, medicines, East Africa.

\section{INTRODUCTION}

Counterfeit drugs are growing global public health problem causing death, disability and injury. No country, developed or developing, can be reported to be free of this problem. The United Nations Office on Drugs and Crime (UNODC) reports that when patients receive counterfeit medicines, they are subjected to multiple risks such as unexpected side effects, allergic reactions, or a worsening of their medical condition. Counterfeit products may not contain any active ingredients, may contain incorrect ingredients, improper dosages of the correct ingredients, or they may contain hazardous ingredients.(1) Additionally, patients may lose confidence in their Physicians, Pharmacists, Nurses and other health care
Professionals, and potentially in modern medicine or the Pharmaceutical Industry.(2)

Like many other public health problems, the counterfeiting of medicine is an important issue that should receive careful attention especially in developing countries. However, the point at which to start tackling this problem is still unclear in many parts of the world, especially in Africa. Invariably, after manufacture, medicinal products may be transferred through several hands before reaching the patients. Even in developed countries, distributors and other handlers have been identified as some of the most critical links in the legitimate pharmaceutical supply chain and therefore potential points of entry for most counterfeit medicines. $(3,4)$ 
Counterfeit medicines have been discovered at various points in the supply chain: at the industry, wholesale, packaging, distribution and marketing, pharmaceutical services providers and healthcare levels. $(5,6)$ In the developing world, the situation is worsened by the inadequate and poor enforcement of existing regulations. $(7,8)$ Counterfeit medication use contributes significantly to the high morbidity and mortality. The use of counterfeit medication especially in the three major diseases with high mortality in Africa (Malaria, TB and HIV/AIDS) is a common occurrence. High therapeutic drug failure, toxicity, and drug resistance are potential consequences of counterfeit medicine use.

The World Health Organization (WHO) defines counterfeit medications as 'deliberately and fraudulently mislabelled medicines with respect to identity and/or source. Counterfeiting can apply to both branded and generic products and counterfeit products may include products with the correct ingredients or with the wrong ingredients, without active ingredients, with insufficient active ingredient(s) or with fake packaging'. (9) Some tested counterfeit medications contain excessive amounts of active ingredients, the effects of which may be harmful. $(10,11)$

While most studies have focused on how to control the supply of counterfeits, few studies have investigated the risk drivers of increased influx of counterfeited medicines from the perspective of the drug facility owners. This presents an important knowledge gap in counterfeit medicines control. It is in view of this gap that this study was constructed to explore other factors that influence the influx of counterfeit medicines in East Africa (Kenya, Tanzania, Uganda and DRC). The survey sought to assess 1) The risk drivers associated with counterfeit medication proliferation at supply and/or practice level; 2) the impact of regulatory guidelines on practice in the region; 3 ) The level of awareness of practicing pharmaceutical personnel on the magnitude and extent of counterfeit medication use; 4) the parameters that practicing personnel use to detect counterfeit drugs as well as the steps undertaken after encountering a counterfeit drug.

\section{METHODS}

This descriptive cross-sectional survey was conducted in 2009. A list of selected drug outlets in Malaba (Kenya), Busia(Uganda), Bukavu (DRC), Tunduma and Dar es Salaam (Tanzania) was populated beforehand. All of the drug outlet owners on the list were contacted for individual face-to-face interviews.

This survey was part of a service evaluation undertaken to benefit the community members who source their medication from the drug stores and was designed and conducted solely to define or judge current service. It involved no change to the standard service being delivered in the areas and therefore did not require ethical approval. Furthermore, the data is completely anonymous, it is not possible to identify the participants and use of the data cannot cause substantial damage and distress.

A semi-structured questionnaire was prepared for the interview. It focussed on drug store owners' practices and perceptions surrounding counterfeit medicine issues. These were categorised as questions related to the following: 1) attributes of the respondent and facility/drug store 2) perception and practices related to medicine types, sources and procurement 3 ) perceptions and practices related to medicine quality and counterfeit drugs and 4) observation on handling counterfeit medicines and their risk drivers. The questionnaire was translated into the appropriate local language for each of the selected study sites.

All members of the interview teams were provided with the necessary training to prevent biases. The questionnaire was then pre-tested among different retailers in Malaba (Uganda) and edited before starting the final survey. Interviewers contacted owners of the drug stores and explained the reason for the study to the respondents and requested their cooperation. The respondents were encouraged to reply honestly and without apprehension. Interviewers explained to respondents that there was no threat of future action based on their responses and that all information would be handled maintaining utmost confidentiality and upholding research ethics. For anonymity and accountability, each of the filled-out questionnaires was given a specific interview 
number immediately following its completion. Basic data analysis was performed using Excel. Only relevant significant associations are reported in the results section.

\section{RESULTS}

\section{Attributes of the respondent and facility/drug} store
A total of 171 drug outlets in the selected sites were included in the survey $(45,31,45$ and 50 in Uganda, Kenya, DRC and Tanzania respectively). Of these, $99 \%$ are privately owned while $1 \%$ are government owned. Drug shops constituted $52 \%$ of the drug outlets followed by pharmacies, clinics and hospitals (38\%, $7 \%$ and $1 \%$ respectively). (Figure 1 )

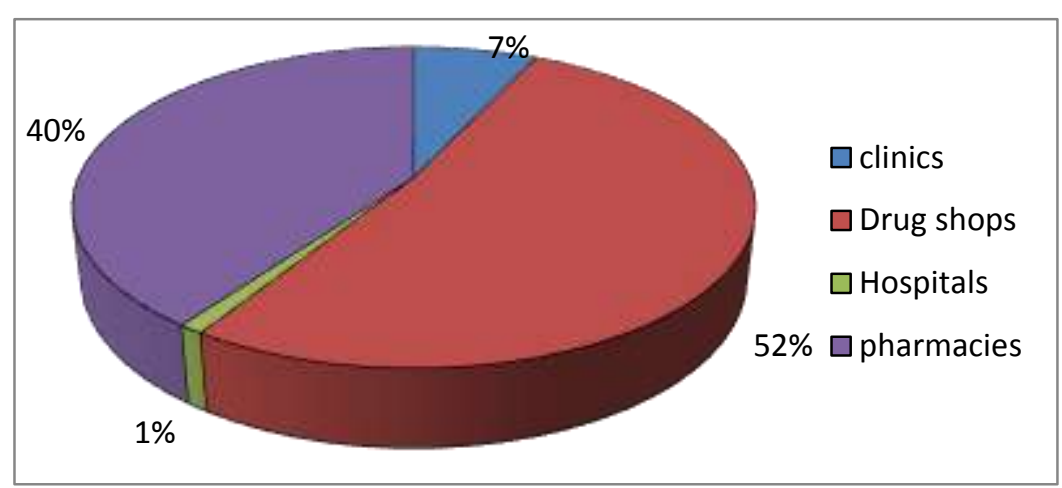

Figure 1: Categories of the medicines outlets involved in the study.

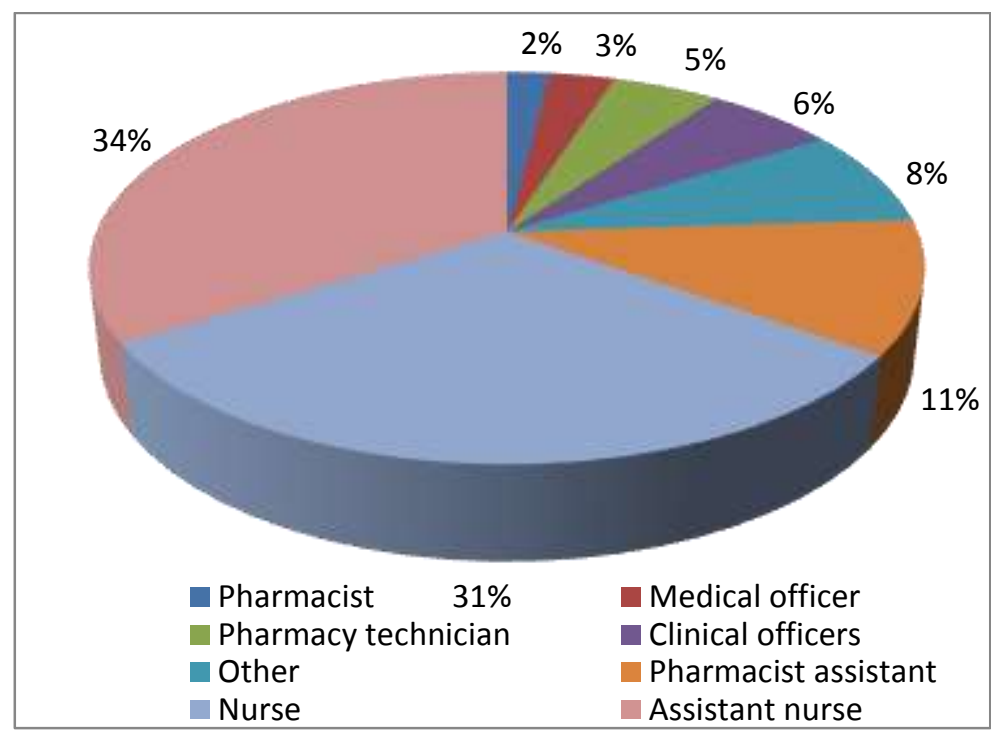

Figure 2: Different practice categories of the personnel working in the 171 drug stores.

Perception and practices related to medicine types, sources and procurement

To assess some of the risk drivers to counterfeit medication use, the interviewees were asked to rank the influence of product quality, price, availability, and market demand on the decision to purchase or choice of pharmaceutical products. Of the 171 interviewees 22 ranked quality and price as the least important aspects they considered when procuring drugs. These two attributes, quality and price, when making a supply purchase decision, may potentially fuel the injection of counterfeit medications.

\section{Suppliers}

Generally, $65.9 \%$ of the drug store owners sourced their supplies from registered warehouses/wholesalers while the remaining $34.1 \%$ were supplied by unregistered in-country or cross-border sales representatives, retail pharmacies as well as from other drug shops. $45 \%$ of the interviewees in Tunduma and Dar es Salaam reported procuring their drugs from 
vendors who walk into their drug outlets, $25 \%$ procure their drugs based on referrals, and $30 \%$ procure their drugs from both referrals and vendors that walk into their outlets. Supplies deliver within one day in $63.6 \%$ of the cases. In Malaba and Busia, $93.2 \%$ of the personnel procure their drugs based on both referrals and from vendors that walk into their outlets and have supply lead time of one day in $43.2 \%$ of the cases. In DRC $85.7 \%$ of the drug store personnel procure their drugs based on referrals with all the personnel receiving their drug supplies within the same day.

In all the towns covered in the four countries, the 10 fastest moving drugs, according to product labelling, were reported to come from 27 different countries with India ranking highest with 532 different products. (Figure 3)

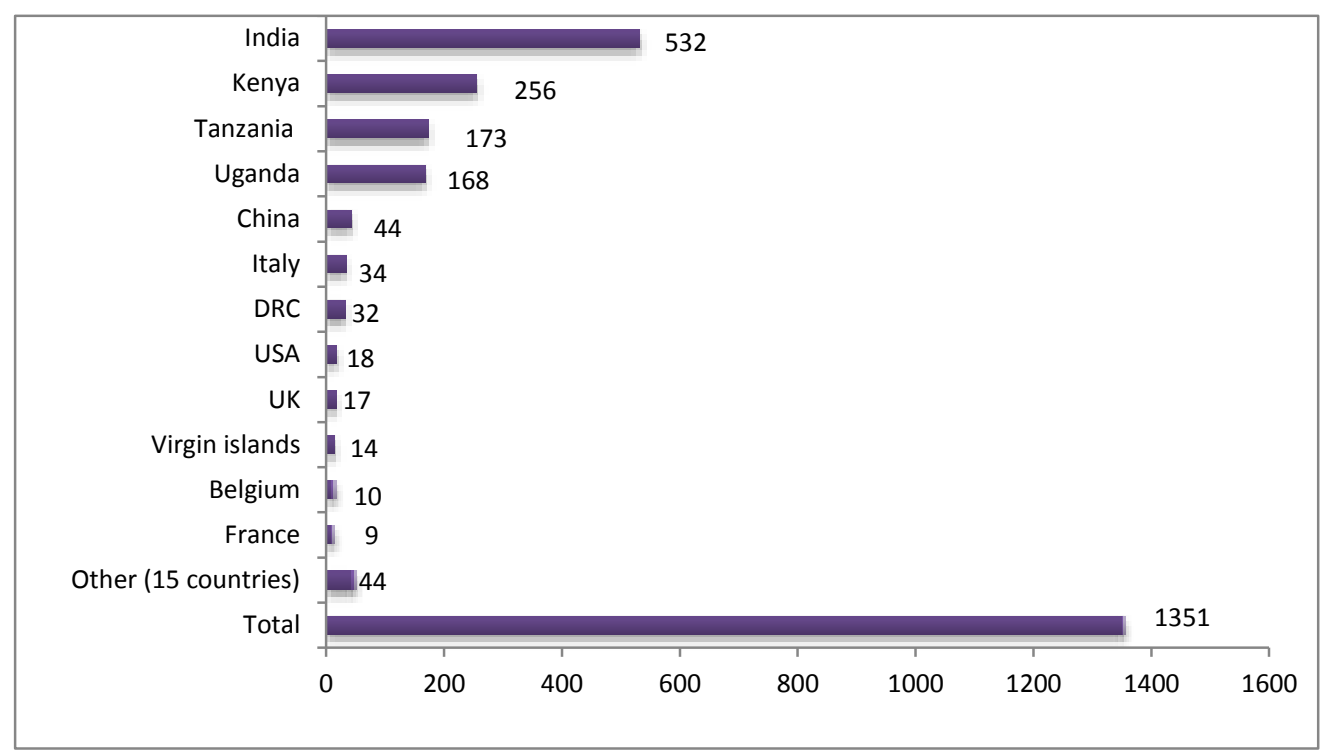

Figure 3: Countries of origin of the 10 fastest moving drugs in each drug outlet according to product labelling

\section{Counterfeit drugs}

Of the 171 interviewees, 135 acknowledged that they were aware of the existence of counterfeit drugs. 106 of these attributed their level of awareness to mass media. Only 32 of the interviewees reported having received any formal education and/or training on counterfeit medicines at seminars or workshops. A large number of the interviewees (160) acknowledged that counterfeit drugs pose a major threat to the patient and pharmaceutical market. (Table 1)

Table 1: Knowledge and perceptions of drug store owners

\begin{tabular}{|l|c|c|c|c|}
\hline \multicolumn{1}{|c|}{ Country } & $\begin{array}{c}\text { Aware of } \\
\text { existence of } \\
\text { counterfeits }\end{array}$ & $\begin{array}{c}\text { Heard from } \\
\text { Mass media of } \\
\text { counterfeits }\end{array}$ & $\begin{array}{c}\text { Formal training } \\
\text { on Counterfeits }\end{array}$ & $\begin{array}{c}\text { Knowledge that } \\
\text { counterfeits are } \\
\text { threats }\end{array}$ \\
\hline $\begin{array}{l}\text { Tumduma/Dar } \\
\text { es Salaam }\end{array}$ & 48 & 33 & 3 & 41 \\
\hline Kenya/Uganda & 46 & 53 & 4 & 75 \\
\hline $\begin{array}{l}\text { Bukavu } \\
\text { (DRC) }\end{array}$ & 41 & 20 & 25 & 44 \\
\hline
\end{tabular}




\section{Tunduma and Dar es Salaam}

$45 \%$ of the drug outlet owners reported that the most important consideration in determining if a product was counterfeit was the labelling of the product $(45 \%)$, followed by the product packaging (35\%). The third aspect that they would look for is quality of the product (25\%), expiry date $(4 \%)$, batch number $(2 \%)$ and odour
(2\%) of the product. Given the close resemblance with which counterfeits drugs have to the original brands, most personnel may not be able to detect counterfeit drugs based entirely on these parameters. The interviews revealed a number of drugs encountered as being counterfeit in the region (Table 2) as well as their suspected countries of origin. (Figure 4)

Table 2: Encountered counterfeit drugs in Tunduma and Dar es Salaam

\begin{tabular}{|l|c|}
\hline \multicolumn{1}{|c|}{ Name of product } & $\begin{array}{c}\text { No. of } \\
\text { encounters }\end{array}$ \\
\hline Albendazole & 1 \\
\hline Ciprofloxacin & 1 \\
\hline $\begin{array}{l}\text { Gentrisone cream (betamethasone, gentamicin and } \\
\text { clotrimazole) }\end{array}$ & 5 \\
\hline Metakelfin (pyrimethamine and sulphamethoxypyrazine) & 17 \\
\hline Chapa shoka & 3 \\
\hline Sapati lotion (antifungal) & 3 \\
\hline B-tex ointment(ayurvedic anti-infective) & 3 \\
\hline Coldril capsules & 3 \\
\hline Cold cap & 3 \\
\hline Coldaur capsules & 2 \\
\hline Sildenafil & 1 \\
\hline
\end{tabular}

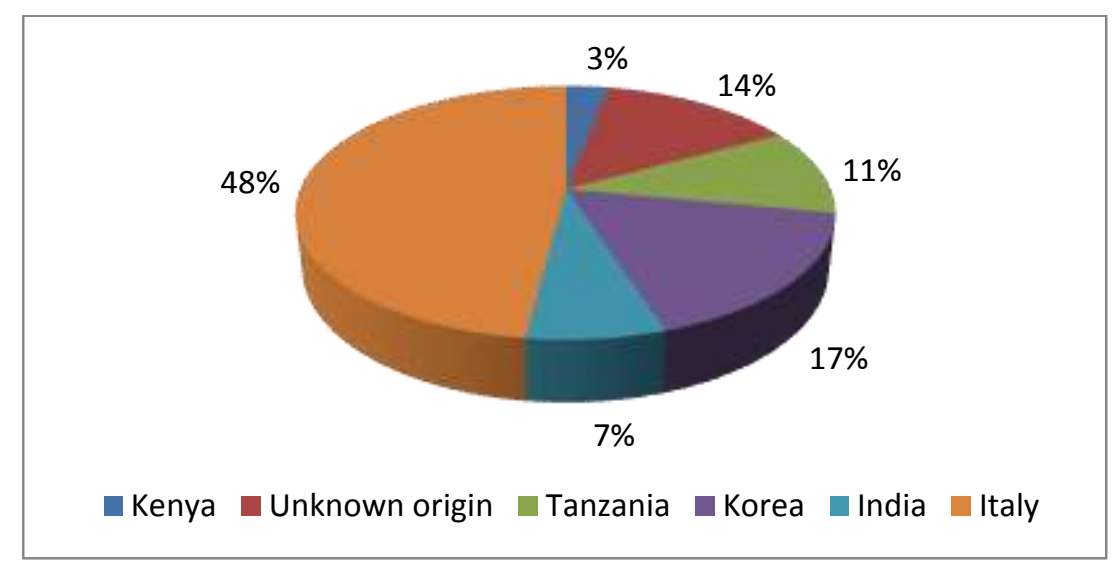

Figure 4 : The names of the countries the counterfeit drugs were labelled as coming from.

When asked what it was about the suspected counterfeit drugs that triggered suspicion, three of the interviewees said that it was as a result of a discrepancy in labelling, five as a result of poor packaging and four said the products were of poor physical quality. The majority detected the counterfeits from the poor packaging, physical quality and labelling. After encounter with the suspected counterfeit drugs, $75 \%$ of the cases were reported. Of those reported, only $32 \%$ were reported to the drug regulatory authority, $8 \%$ to the health inspector, $36 \%$ to other drug store owners, and $24 \%$ to the patient. 


\section{Malaba and Busia (Kenya/Uganda)}

74 drug outlet interviewees gave several parameters that they use to determine if a product is a counterfeit and its quality. Most used the physical features of the product (35\%), the expiry date $(20 \%)$ and the product labelling $(12 \%)$. Only a few said that they would consider the supplier's reputation (9\%), batch number $(6 \%)$, quality $(1 \%)$, and the product seal $(1 \%)$. $2.7 \%$ ( 2 interviewees) reported that they had had a recent encounter with a pharmaceutical product that they thought was counterfeited (Table 3). When asked how they managed to detect the counterfeit drugs they both cited a discrepancy in product labelling and physical quality.

Table 3: Encountered counterfeit drugs in Kenya and Uganda

\begin{tabular}{|l|c|}
\hline \multicolumn{1}{|c|}{ Name of product } & Name of encounters \\
\hline $\begin{array}{l}\text { Cefuroxime } \\
\left.\text { (Zinnat }{ }^{\circledR}\right)\end{array}$ & 1 \\
\hline Sildenafil & 1 \\
\hline
\end{tabular}

\section{Bukavu (Democratic Republic of Congo)}

In order to detect the counterfeit drugs, $36 \%$ of the personnel said that they looked at both product labelling and quality, while $25 \%$ said that they had looked at the quality of the product. Several interviewees in Bukavu reported that they had had a recent encounter with a pharmaceutical that they suspected to be counterfeit based on poor labelling and physical appearance. (Table 4)

\section{Table 4: Encountered counterfeit drugs in DRC}

\begin{tabular}{|l|c|}
\hline Name of drug & Frequency \\
\hline Ampicillin & 6 \\
\hline Arinate & 36 \\
\hline Quinine & 4 \\
\hline Papaverine & 5 \\
\hline Artemether & 12 \\
\hline Chloroquine & 2 \\
\hline Codeine & 1 \\
\hline Ibuprofen & 1 \\
\hline Erythromycin & 1 \\
\hline Amoxycillin & 1 \\
\hline Tetracycline & 3 \\
\hline Paracetamol & 1 \\
\hline
\end{tabular}

$97.5 \%$ (39) of the interviewees said that they reported the incidences to the regulatory authority and/or the patient. (Table 5)

\section{Regulatory Aspects}

Almost all of the respondents were aware of the existence of the drug regulatory authority in their country, were registered, and reported periodic regulatory inspections. Unfortunately however, only between $3-36.1 \%$ reported any knowledge or existence of drug regulations. (Table 5)

Table 5: Awareness and knowledge of drug regulatory policy

\begin{tabular}{|l|c|c|c|c|}
\hline \multicolumn{1}{|c|}{ Country } & $\begin{array}{c}\text { Knowledge of } \\
\text { drug } \\
\text { regulations (\%) }\end{array}$ & $\begin{array}{c}\text { Knowledge of } \\
\text { drug regulatory } \\
\text { Authority (\%) }\end{array}$ & Registered (\%) & $\begin{array}{c}\text { Regulatory } \\
\text { Affairs } \\
\text { Inspection (\%) }\end{array}$ \\
\hline $\begin{array}{l}\text { Tunduma/ } \\
\text { Dar es Salaam } \\
\text { (Tanzania) }\end{array}$ & 36.1 & 98 & 93 & 100 \\
\hline $\begin{array}{l}\text { Busia/Malaba } \\
\text { Kenya/Uganda) }\end{array}$ & 3 & 100 & 82.2 & 97 \\
\hline Bukavu (DRC) & 27.3 & 97 & 97.8 & 100 \\
\hline
\end{tabular}

\section{DISCUSSION}

The findings of this survey suggest that drug outlet owners procure their products from different sources, suppliers and distributors and that these multiple actors in the supply chain may potentially increase the risk of proliferation of counterfeit products if regulation is poor or inadequate. The survey was limited in that it was not conducted by professional interviewers, 
where, teams were deployed for the interviews and interviews were conducted in several local languages. Consequently, it was not possible to completely rule out the possibility of interviewer bias. However, to minimise such bias, training and feedback discussions were held after the interviews. Another limitation of the survey was that it was only conducted in certain cities/towns of the region and may not comprehensively represent the drug outlet owners' perception and practices on dealing with medicines in the whole East African region. However, the results present critical baseline information on the region's drug store/outlet owners and could help regulators take future steps with more in-depth and country/site-specific studies.

Some of the respondents in this survey did not have a clear understanding of the concept of counterfeit medicines and were unaware of what they should do if they suspect a medicine or medical device was counterfeit. There is a strong and urgent need to orient and sensitise drug store/outlet owners on issues of counterfeit medicines. Anti-counterfeit measures need to be incorporated into a set of guidelines to be developed. (12) This survey found that a very low number of respondents had received any formal training on counterfeit medicines. Therefore, in order to strengthen their awareness as well as regulatory system, informationsharing components in the form of advocacy workshops or meetings should be held on a regular basis.

The main risk drivers attributed to counterfeit medicines being found on the market in the region were found to be 1) higher profit margins compared to genuine medicines; 2) lack of knowledge on how to recognize counterfeit drugs; 3) Ignorance of the existence of the counterfeit drug policy; 4) Unqualified personnel that are involved in the manufacturing, supply chain and medication use process.

\section{CONCLUSION}

Most of peri-urban and rural Africa has a plethora of drug shops run by attendants with varying backgrounds, diverse knowledge on medicines and practice patterns. This review shows that, there is an urgent need for medicine regulators and other stakeholders in involved in medicine safety in the region, to focus on properly regulating these outlets that serve the majority of the population. Additionally, there is need to accredit the personnel, standardize the training and strengthen their knowledge on the ills of falsified and sub-standard drugs. A major proportion of drug store owners interviewed in the region were not properly informed on issues of counterfeit medicine and how to handle such cases. To protect the pharmaceutical supply chain, particularly in the private sector, and the general public from the negative sequelae of counterfeit medicines, drug outlets should be properly regulated, the attendants oriented and sensitised to their dangers, counter measures against and risk drivers of counterfeit medicines.

\section{ACKNOWLEDGEMENT}

This article is made possible by the support of the American People through the United States Agency for International Development (USAID) and the Roads to a Healthy Future (RTHF) project. The contents of this article are the sole responsibility of the authors and do not necessarily reflect the views of USAID, the United States Government, or Howard University.

\section{CONFLICT OF INTEREST}

No conflict of interest declared

\section{REFERENCES}

1. Fake medicines in West Africa a health risk for all [Internet]. West Africa: UNODC; 2009 [cited 2014 June]. Available from:

http://www.unodc.org/unodc/en/frontpage/2009/J uly/fake-medicines-pose-health-risk-in-westafrica.html

2. Nsimba, SE. Problems associated with substandard and counterfeit drugs in developing countries: a review article on global implications of counterfeit drugs in the era of antiretroviral (ARVs) drugs in a free market economy. East Afr J Public Health. 2008 Dec;5(3):205-10.

3. Tetteh E. Creating reliable pharmaceutical distribution networks and supply chains in African countries: Implications for access to medicines. Research in Social and Administrative Pharmacy. 2009; 5:286-97.

4. Lewis M. Wholesalers called weak link in pharmaceutical supply chain. Drug Topics United States; 2004.

5. Medicines and Healthcare products Regulatory Agency's (MHRA). Anti-Counterfeit Strategy.: Anti-counterfeiting strategy 2007-2010 
[Internet]. 2007. [cited 2014 June 03]. Available from:

http://www.mhra.gov.uk/home/groups/ei/docume nts/websiteresources/con2033156.pdf/

6. Cohen JC, Mrazek M, Hawkins L. Tackling Corruption in the Pharmaceutical Systems Worldwide with Courage and Conviction. Clinical Pharmacology \& Therapeutics 2007; 81:445-9.

7. Mohamed GK. The impact of the pharmaceutical regulations on the quality of medicines on the Sudanese market: Importers' perspective. Sudanese Journal of Public Health. 2007; 2:15767.

8. Raja MR G, Venkatesh MP, Achin J, Pramod KTM. Regulatory Perspectives Of Pharmaceutical Products In Ghana. International Journal of Drug Regulatory Affairs. 2014; 2(2): 7-15.

9. World Health Organization. General information on counterfeit medicines: definition [Internet]. 2009. [cited 2014 June]. Available from: http://www.who.int/medicines/services/counterfe it/overview/en

10. Catizone CA. Counterfeit drugs and states' efforts to combat the problem. Journal of Pharmacy Practice. 2006; 19: 165-70.

11. Jackson G, Arver S, Banks I, Stecher VJ. Counterfeit phosphodiesterase type 5 inhibitors pose significant safety risks. International Journal of Clinical Practice. 2010; 64: 497-504.

12. World Health Organisation. Technical Report Series 957: WHO Expert Committee on Specifications for Pharmaceutical Preparations (annex 5). Geneva, Switzerland: World Health Organization; 2010. 